\title{
What are the sociodemographic and gender determinants of non-fatal self-harm in older adult users and non-users of antidepressants? A national population- based study
}

Khedidja Hedna ${ }^{1,2^{*}}$ (D) Johan Fastbom ${ }^{3}$, Ingmar Skoog ${ }^{1,4}$, Gunnel Hensing ${ }^{5}$ and Margda Waern ${ }^{1,6}$

\begin{abstract}
Background: Late-life self-harm (SH) is often linked to depression. However, very few studies have explored the role of other factors and their interaction with depression in the occurrence of late-life SH. The objective of this research was to examine sociodemographic and gender factors associated with non-fatal $\mathrm{SH}$, in older adults with and without antidepressant therapy.
\end{abstract}

Methods: We used national longitudinal register data from a total cohort of all Swedish residents aged $\geq 75$ years between 2006 and $2014(N=1,413,806)$. Using personal identity numbers, we linked individuals' data from numerous national registers. We identified all those with at least one episode of non-fatal self-harm (regardless of level of intent to die) and matched 50 controls to each case. A nested case-control design was used to investigate sociodemographic factors associated with non-fatal SH in the total cohort and among antidepressant users and nonusers. Risk factors were analysed in adjusted conditional logistic regression models for the entire cohort and by gender.

Results: In all, 2242 individuals had at least one episode of a non-fatal SH (980 men and 1262 women). Being unmarried was a risk factor for non-fatal SH in men but not in women. Among users of antidepressants, higher non-fatal SH risk was observed in those born outside the Nordic countries (IRR: 1.44; 95\% Cl: 1.11-1.86), whereas in AD non-users increased risk was seen in those from Nordic countries other than Sweden (IRR: 1.58; 95\% Cl: 1.08-2.29). Antidepressant users with higher education had an increased risk of non-fatal SH (IRR: 1.34; 95\% Cl: 1.12-1.61), in both men and women.

Conclusions: Foreign country of birth was associated with increased risk for non-fatal SH in older adults with and without AD therapies. Being married was a protective factor for non-fatal SH in men. The complex association between sociodemographic factors and use of antidepressants in the occurrence of self-harm in older men and women indicates the need for multifaceted tailored preventive strategies including healthcare and social services alike.

Keywords: Pharmacoepidemiology, Sociodemographic factors, Self-harm, Cohort study, Older adults, Antidepressants, Registries

\footnotetext{
* Correspondence: Khedidja.hedna@neuro.gu.se

${ }^{1}$ Center for Ageing and Health (Age Cap), Department of Psychiatry and Neurochemistry, Gothenburg University, SE-413 45 Gothenburg, Sweden

${ }^{2}$ Statistikkonsulterna Jostat \& Mr Sample AB, Gothenburg, Sweden

Full list of author information is available at the end of the article
}

(c) The Author(s). 2020 Open Access This article is licensed under a Creative Commons Attribution 4.0 International License, which permits use, sharing, adaptation, distribution and reproduction in any medium or format, as long as you give appropriate credit to the original author(s) and the source, provide a link to the Creative Commons licence, and indicate if changes were made. The images or other third party material in this article are included in the article's Creative Commons licence, unless indicated otherwise in a credit line to the material. If material is not included in the article's Creative Commons licence and your intended use is not permitted by statutory regulation or exceeds the permitted use, you will need to obtain permission directly from the copyright holder. To view a copy of this licence, visit http://creativecommons.org/licenses/by/4.0/ The Creative Commons Public Domain Dedication waiver (http://creativecommons.org/publicdomain/zero/1.0/) applies to the data made available in this article, unless otherwise stated in a credit line to the data. 


\section{Background}

Non-fatal self-harm $(\mathrm{SH})$ is a significant risk factor of subsequent suicidal behaviour in late-life [1]. Given the high rates of suicide in persons aged 70 and above, especially in men [2], and the high intent to die observed in older adult suicide attempters [3], exploring factors associated with non-fatal SH may help to inform interventions to prevent suicide. Research conducted in that field, however, tends to include a wide age range when defining older adulthood, with some including persons in their fifties $[4,5]$. Further, many studies are hospitalbased [1]. Since SH in late-life has distinct characteristics compared to younger populations [1], there is a need for research within a broader public health context, focusing on older adults in the general population.

Among adults who seek mental health care, the link between depression and suicide is particularly strong in those over the age of 75 [6], and most suicide prevention strategies have focused on the optimisation of the diagnosis and treatment of late-life depression [7]. However, it is critical to also explore the role of sociodemographic factors and their interaction with depression in the occurrence of late-life SH [1]. Further, very few studies have investigated the associated gender differences, and studies that focus specifically on those above the age of 75 are uncommon [8].

Large population-based studies provide a useful context and enough power to examine these factors without selection bias. We recently applied this approach to a study in adults aged 75 and above who were new users of antidepressant (AD) therapy [9]. We found an increased risk of non-fatal $\mathrm{SH}$ in women born outside of Nordic countries, but not men, and in those with higher education [9]. We therefore aimed to extend findings from our previous study and to explore the factors associated with non-fatal $\mathrm{SH}$ in the total population aged $75+$, and with respect to treatment with AD.

\section{Methods}

\section{Study population}

Swedish residents aged $\geq 75$ years (mean age 80.5 years; range 75-114) between January 1, 2007 and June 30, 2014 $(N=1,415,386)$ were included in a populationbased register study and followed until December 31, 2014 or until date of emigration or death. About three out of five were women (58\%), about half (47\%) were married and nine out of 10 were born in Sweden (89\%). Half of the population had compulsory school only (51\%); a similar proportion (46\%) had a blue-collar occupation before retirement. Nearly one-tenth (9\%) resided in an institution.

A person was considered to be an $\mathrm{AD}$ user if a prescription for any non-tricyclic AD was redeemed for this individual during the study period according to the
Swedish Prescribed Drug Register. We excluded those who used exclusively tricyclic $\mathrm{AD}$, which are primarily prescribed for pain in Sweden today. The AD user cohort had higher proportions of women (67\% vs $54 \%$ in non-users of AD), widows/widowers (43\% vs $30 \%$ in non-users) and persons residing in institutions (21\% vs $4 \%$ in non-users).

\section{Data sources}

Data from national registers were merged through the unique personal identity number [10]. Users of AD were identified from the Swedish Prescribed Drug Register held at the National Board of Health and Welfare [11]. The register contains data with unique personal identifiers of all persons with redeemed prescriptions in the community, residential care and nursing homes. The National Patient Register, which includes all inpatient and specialised outpatient healthcare contacts, was used to identify individuals with non-fatal SH. Sociodemographic and emigration data were collected from Statistics Sweden. Persons residing in institutions were identified by the National Care and Social Services database. Death data were retrieved from the Cause of Death Register.

\section{Study outcomes}

Persons with non-fatal SH (regardless of level of intent to die) were identified based on the International Classification of Disease (ICD)-10: Intentional SH (X60-X84), harm of undetermined intent (Y10-Y34), sequelae of intentional $\mathrm{SH}$ (Y87.0) and events of undetermined intent (Y87.2).

\section{Sociodemographic characteristics}

Sociodemographic characteristics included: sex, age group (75-79, 80-84, 85-89, and $\geq 90$ years), marital status (single, married, divorced, and widow/widower), country of birth (Sweden, other Nordic countries, and outside of Nordic countries), highest level of education (primary (compulsory), secondary, and higher education), category of employment at retirement (upper white-collar; lower white-collar; blue-collar and others), residence in institution at baseline. Annual disposable household income was categorised into quartiles.

\section{Statistical analysis}

We first assessed the incidence rates of non-fatal $\mathrm{SH}$ in the total cohort and in users and non-users of AD. Then, employing a nested case-control design, persons with non-fatal $\mathrm{SH}$ were individually matched to 50 controls from the same age, sex, and time-specific risk set. For persons with more than one episode of non-fatal SH during the study period, we only considered as outcome the first episode that occurred during the study period. 
We generated conditional logistic regression models to estimate incidence rate ratios (IRR) in the total cohort and in AD users and non-users separately [12]. We fitted sex interaction terms and formally tested their significance. Analyses were then stratified by gender. We added to the adjusted regression models the following potential confounders: the concomitant use of other psychoactive medications, occurrence of non-fatal SH in the preceding year and use of specialised psychiatric care as a proxy for more serious mental disorder. The rationale for the latter is that milder forms of depression are treated within primary care in Sweden; more serious cases are referred to specialised care. The analyses were conducted using SAS statistical software version 9.4 (SAS Institute Inc., NC, USA).

\section{Results}

In all, 2242 individuals (980 men and 1262 women) had at least one non-fatal $\mathrm{SH}$ episode during the study period (Table 1). The incidence rate of non-fatal $\mathrm{SH}$ among AD users was 178.6 per 100,000 person-years, a rate about 17 times that in the non-user group (10.5 per 100,000).

\section{Total cohort}

Being unmarried and being foreign born were associated with higher risk for non-fatal SH (Fig. 1). The detailed results of the regression analyses are shown in the Additional file 1. Lower risk for non-fatal SH was found in those living in institutions at baseline (IRR: 0.23 ; 95\% CI: $0.19-0.29$ ) and those aged 80 and above, The risk for non-fatal $\mathrm{SH}$ was slightly higher in those with higher education compared to those with only compulsory education (IRR: 1.18, 95\% CI: $1.01-1.37)$.

\section{Antidepressant users and non-users}

Figure 1 shows that in AD users, age $\geq 80$ years was associated with decreased risk for non-fatal SH. An increased risk was found among those with higher education (IRR: 1.34; 95\% CI 1.12-1.60).

In non-users of $\mathrm{AD}$, increased risk for non-fatal $\mathrm{SH}$ was found in those born in other Nordic countries (IRR: 1.58; 95\% CI 1.08-2.29).

\section{Gender-stratified analyses \\ Men}

In the total cohort, being unmarried was a risk factor for non-fatal SH (single, IRR: 1.61, 95\% CI 1.25-2.08; widowed, IRR: 1.33, 95\% CI 1.10-1.62; divorced, IRR: 1.45, 95\% CI 1.18-1.78) (Fig. 2 and Additional file 2). A higher risk was found in those born outside of Nordic countries (IRR: 1.51; 95\% CI: 1.11-2.07). In AD users, higher risk was found in the divorced (IRR: 1.37; 95\% CI: 1.06-1.78).

\section{Women}

In the total cohort, being foreign-born was associated with increased risk of non-fatal SH. This was the case in those born outside of the Nordic countries (IRR: 1.44; 95\% CI: 1.06-1.97), as well as in those from other Nordic countries (IRR: 1.50 ; 95\% CI: $1.16-1.94$ ). In AD users, the risk of non-fatal $\mathrm{SH}$ was lower in those who were blue-collar workers before retirement (IRR: 0.68; 95\% CI 0.53-0.87).

\section{Methods of non-fatal SH}

Methods of non-fatal SH are shown in Fig. 3. In both genders, poisoning followed by use of sharp objects were the most common methods of non-fatal self-harm. No significant difference in methods of non-fatal $\mathrm{SH}$ was observed between users and non-users of AD.

Table 1 Numbers and incidence rates of men and women with non-fatal self-harm in the total Swedish population aged $\geq 75$ years and in antidepressants users and non-users

\begin{tabular}{|c|c|c|c|c|c|}
\hline & & $\mathrm{N}$ & Person-years & $\begin{array}{l}\text { Persons with } \\
\text { non-fatal } \\
\text { self-harm (N) }\end{array}$ & $\begin{array}{l}\text { Incidence rate of } \\
\text { non-fatal self-harm } \\
\text { per } 100,000 \\
\text { person-year }\end{array}$ \\
\hline \multirow[t]{3}{*}{ All 75+ } & All 75+ & $1,413,806$ & $6,106,791$ & 2242 & 36.7 \\
\hline & Men & 596,652 & $2,570,948$ & 980 & 38.1 \\
\hline & Women & 817,154 & $3,535,843$ & 1262 & 35.7 \\
\hline \multirow[t]{3}{*}{ Non-users of $A D$} & All 75+ & $1,004,641$ & $5,085,385$ & 534 & 10.5 \\
\hline & Men & 462,365 & $2,269,389$ & 310 & 13.7 \\
\hline & Women & 542,276 & $2,815,996$ & 224 & 8 \\
\hline \multirow[t]{3}{*}{ Users of $A D$} & All 75+ & 373,661 & 826,390 & 1476 & 178.6 \\
\hline & Men & 123,096 & 241,672 & 592 & 245 \\
\hline & Women & 250,565 & 584,718 & 884 & 151.2 \\
\hline
\end{tabular}




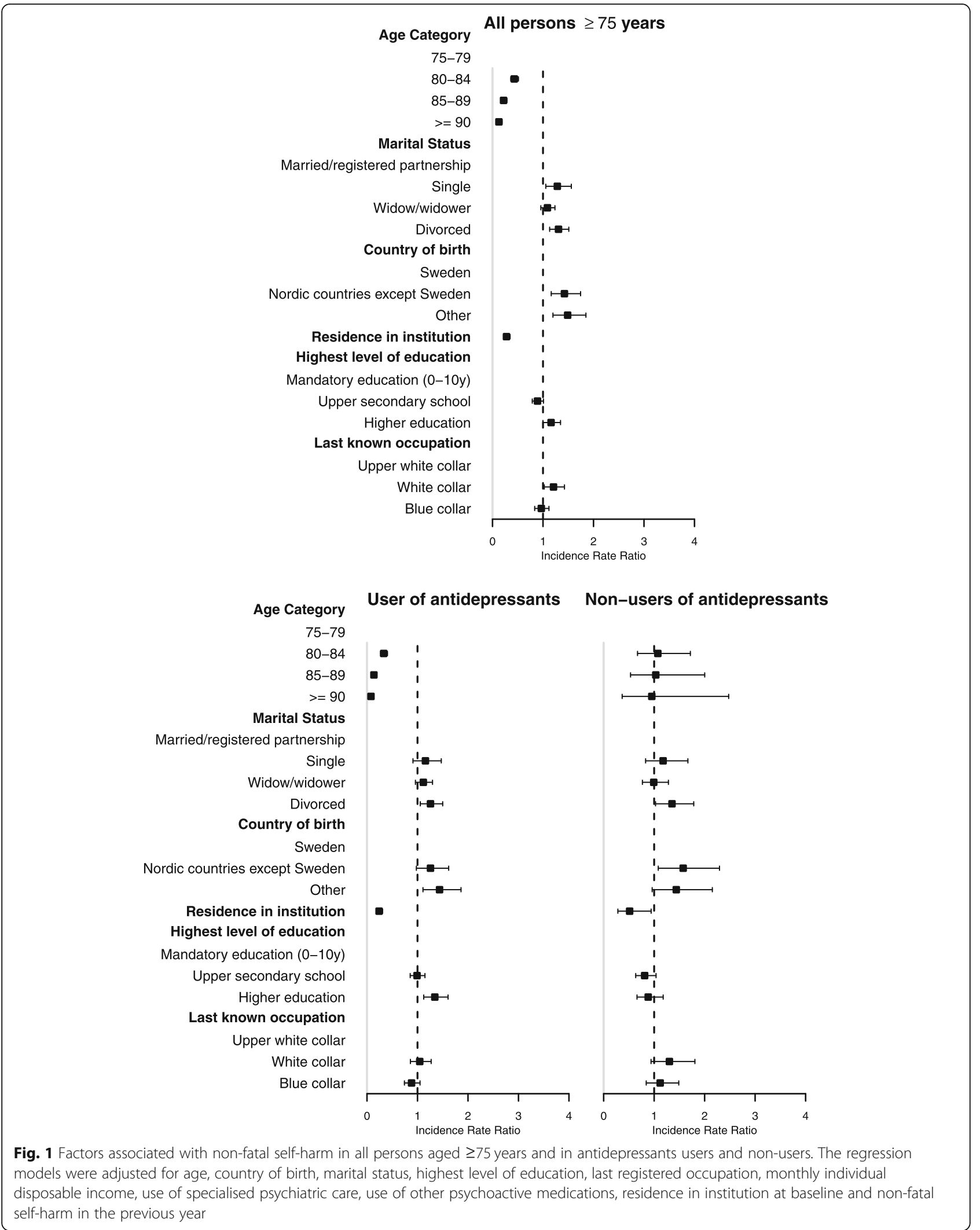




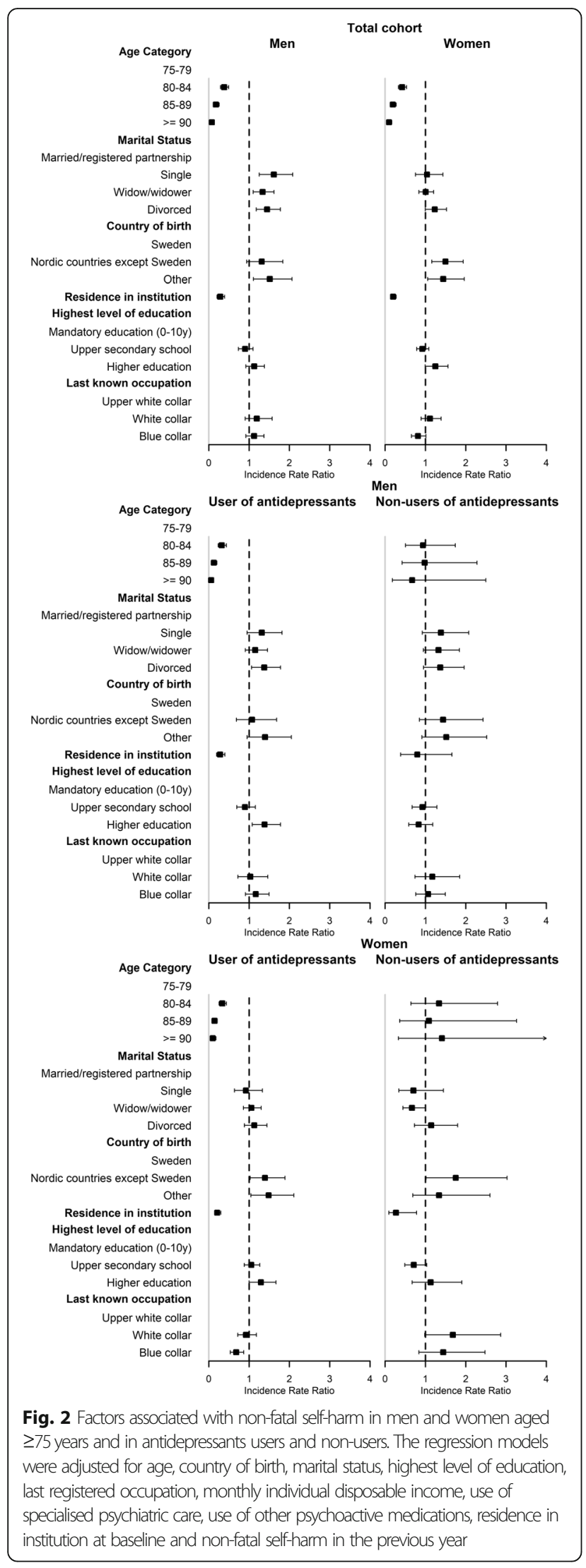

\section{Discussion}

In this national population-based Swedish study, being married was a protective factor for non-fatal $\mathrm{SH}$ in men aged 75 years and above, but not in women. Being foreign-born was associated with an increased risk of nonfatal SH. In AD users, an elevated risk of non-fatal SH was found in both men and women with higher education.

The foreign-born older adults seem to constitute a particular risk group for non-fatal $\mathrm{SH}$. This expands on findings from our previous study that focused only on new users of ADs [9]. Taken together, our results point to a need to improve the monitoring of $\mathrm{AD}$ treatment and to reach the mental health needs of older adults with foreign background. We have previously shown increased risk of suicidal behaviours in older adults with alcohol use disorders [13], and higher rates of alcohol consumption in other Nordic populations might be a partial explanation of our findings [14]. Old migrants are however not a homogeneous group. Further psychosocial studies should be undertaken to identify factors, which may, under certain conditions, influence seeking for mental healthcare and may imply an increased risk of suicidal behaviour, including the motivation for migration and the distance from host culture.

In the total cohort, risk of non-fatal SH was elevated in those with higher education. This was somewhat unexpected, as we have previously reported an association between lower educational level and non-fatal SH in persons aged 70 and above [15]. Our previous study employed a different methodology, involving a clinical cohort and a population-based comparison group. It is probable that depressed older individuals would be less likely to participate in the latter group, which may have affected results. In the current study, the association between higher education and non-fatal self-harm was particularly pronounced in AD users. Loss of social status might help to explain the risk increase, but it is unclear why we did not see an association in the non-user group.

The lower risk of non-fatal $\mathrm{SH}$ in the oldest $\mathrm{AD}$ users $(80+)$ may be explained by the extensive use of ADs in institutions and in those with dementia, which are both associated with lower non-fatal SH risk in our cohort. Frailty and severe illnesses in some institutionalized older adults may make them physically or mentally incapable of planning and carrying out a suicidal act.

Our finding of a protective effect of being married on non-fatal SH in older men is in accordance with previous research [16]. The increased risk observed for single and widowed men, in both AD users and non-users, suggests the need to not only focus on men's use and adherence to prescribed $\mathrm{AD}$ therapies but also to recognise and meet the need of social support in older men without partners who are potentially more prone to social isolation. Our study supports the potential value of mental health 
a. Methods of non-fatal self-harm in older adults (75+) AD users and non-users

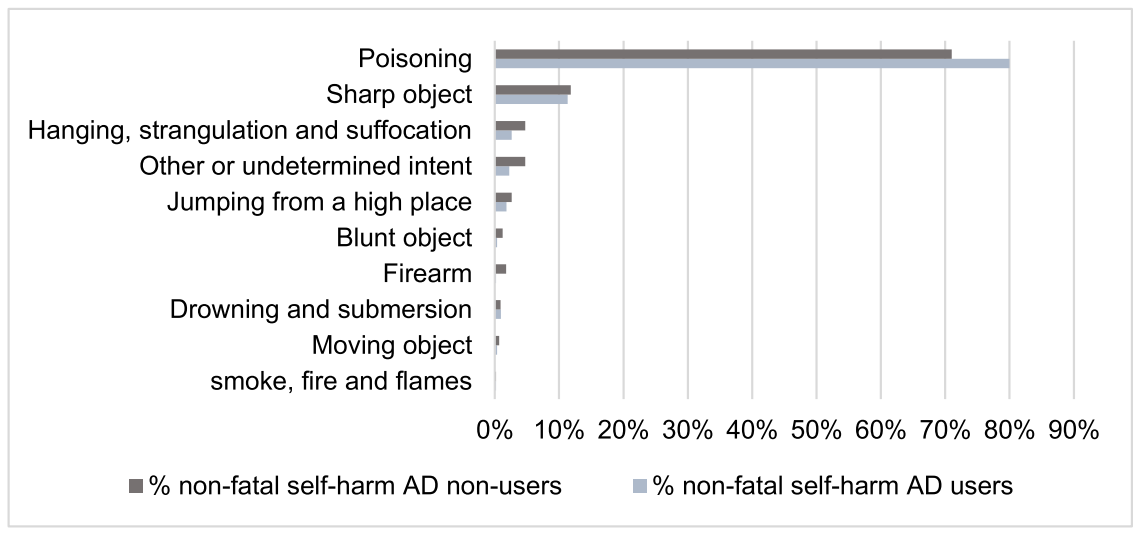

b. Methods of non-fatal self-harm in older men (75+) AD users and non-users

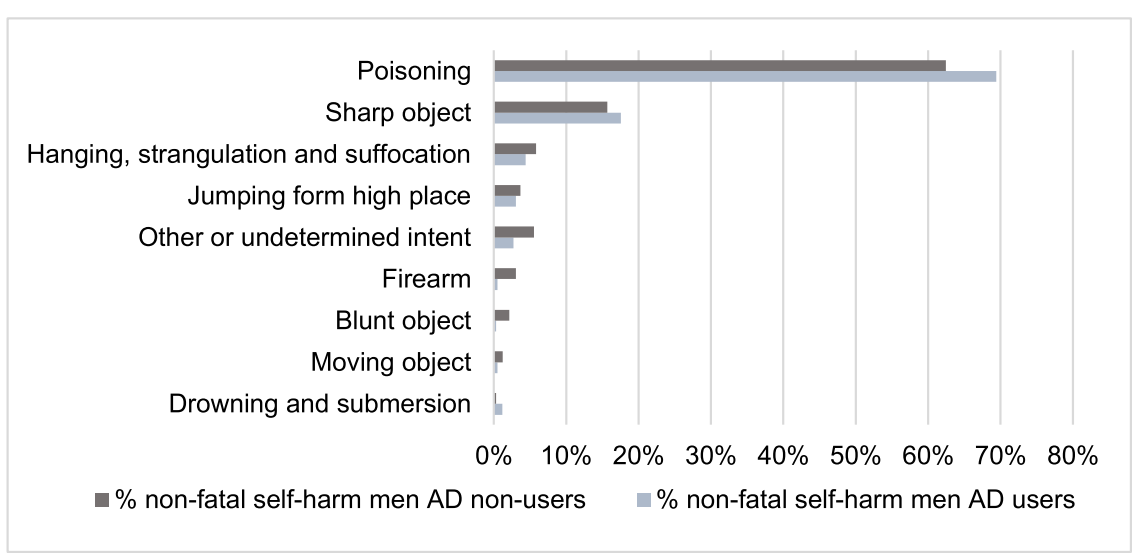

\section{c. Methods of non-fatal self-harm in older women (75+) AD users and non-users}

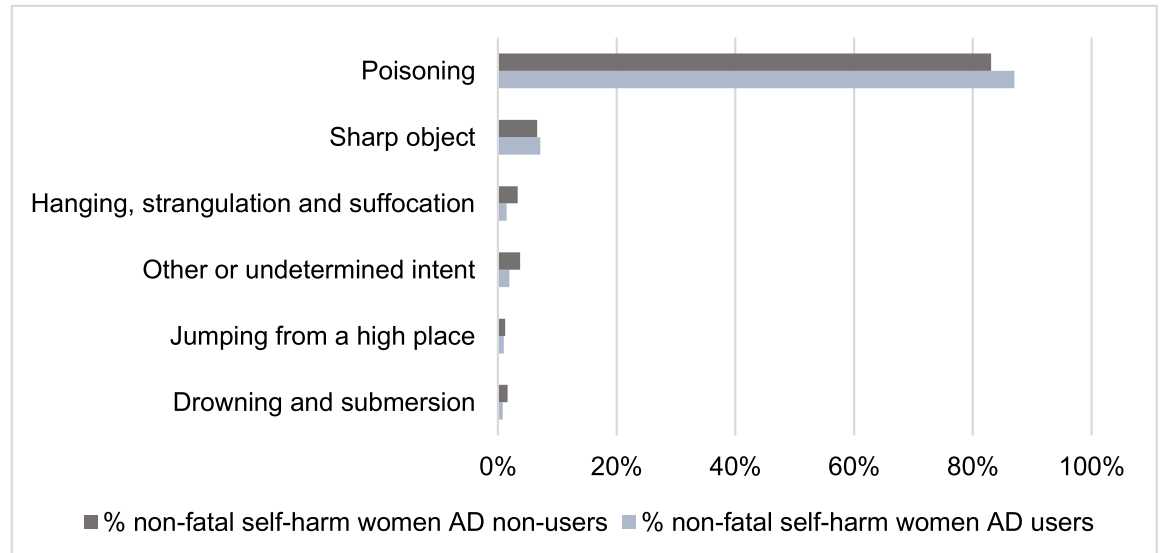

Fig. 3 Methods of non-fatal self-harm in all persons aged $\geq 75$ years and in antidepressants users and non-users 
promotion strategies that encourage men to deconstruct the hegemonic ideal of the man who is emotionally and socially self-sufficient, and to extend their social emotionally supportive relationships other than their partners to achieve this [17].

\section{Methodological considerations}

The use of total population registers provides a more accurate risk estimation as selection bias is eliminated. Further, the large size of the population allowed the inclusion of a wide range of covariates in the adjusted analyses. However, we lacked information on numerous pertinent behavioural risk factors including social isolation, degree of hopelessness, depression severity, problematic alcohol use, and suicidal behaviour earlier in life.

Our study design detected persons who received care in hospital and at specialised outpatient services. The public health significance of studying this group is emphasized by a finding from a British multicentre study estimating that older adult self-harmers presenting to hospital have a risk for suicide that is 67 times that of the general population [18]. However, a limitation of our study is that older adults who self-harmed but did not seek help at hospital or specialised outpatient clinics may have erroneously been considered as controls. This may have caused an underestimation of the risk ratios.

The Swedish Prescribed Drug Register does not include medications prescribed in inpatient settings. As such, there may be a risk that some people classified in this study as non-users of ADs had in fact received this therapy during a hospital stay. We believe this is unlikely to have any noticeable impact on the observed outcome as, in most cases, AD therapy initiated in hospital will be continued after discharge, and thus recorded in the register. The SPDR includes filled prescriptions only, and we are not able to know whether the individuals we identified as users actually took their medications. We note, however, that there is some evidence that older adults taking $\mathrm{AD}$ report that the positive aspects of treatment outweigh the negative [19]. The purchase of AD was used as a proxy for depression in our population but we acknowledge a possibility of an indication bias or a residual confounding as $\mathrm{AD}$ may be prescribed in latelife for other indications than depression [20].

We lacked data on date of immigration which is a limitation since time spent in the host country may influence the degree of acculturation [21]. Our results may not be extrapolated to other regions or cultures due to differing patterns of suicidal behaviours and availability of healthcare.

\section{Conclusion}

The finding of elevated non-fatal $\mathrm{SH}$ risk in persons born outside of Sweden both with and without AD therapies indicates a need for a better understanding of potential barriers to adequate support by mental healthcare service providers, primary care services and social services alike. Considering the risk increase associated with unmarried status in men, there is a special need for interventions that target this group. The complex association between sociodemographic factors and use of antidepressants in the occurrence of self-harm in older men and women highlight the need for more research on tailored multifaceted gender-specific preventive strategies to reduce suicidal behaviour in older adults.

\section{Supplementary information}

Supplementary information accompanies this paper at https://doi.org/10. 1186/s12889-020-08892-2.

Additional file 1. Factors associated with non-fatal self-harm in all persons aged $\geq 75$ years and in antidepressants users and non-users.

Additional file 2. Factors associated with non-fatal self-harm in men and women aged $\geq 75$ years and in antidepressants users and non-users.

\section{Abbreviations}

AD: Antidepressants; Cl: Confidence interval; IRR: Incidence rate ratio; SH: Selfharm; SPDR: Swedish Prescribed Drug Register

\section{Acknowledgements}

The authors would like to thank Maria Persson from Statistikkonsulterna for her guidance on statistical methods and for performing the analyses.

\section{Authors' contributions}

$\mathrm{KH}$ conceived and designed the study, helped acquire the data, helped with data analysis and interpretation of results, drafted the article and had the final approval for submission. GH and IS helped with interpretation of results, revised the article for content and gave the final approval for submission. JF helped to design the study, helped with interpretation of results, revised the article for content and gave the final approval for submission. MW is the primary investigator of the project. She conceived and designed the study, helped acquire the data, helped with interpretation of results, revised the article for content and gave the final approval for submission. The authors read and approved the final manuscript.

\section{Funding}

This work was supported by the Swedish Research Council (VR) (M.W., grant number 2016-01590); the Swedish Research Council for Health, Working Life and Welfare (Forte) (M.W., grant number 2016-07097); ALFGBG (M.W., grant number 715841); and the Söderström-König Foundation (K.H., grant number 844351). The sponsors have no role in the design, methods, subject recruitment, data collection, analysis and preparation of the paper. Open access funding provided by University of Gothenburg.

\section{Availability of data and materials}

The datasets generated and/or analysed during the current study are not publicly available due confidentiality as they include sensitive private information. Aggregated data may be available from Statistics Sweden or from the National Board of Health and Welfare upon request.

\section{Ethics approval and consent to participate}

The study was approved by the Regional Ethical Review Board in Gothenburg (Ethical approval no: 111-15) in accordance with national regulations.

No patients were recruited for this study as it was based solely on national register data. Statistics Sweden replaced the unique personal identity numbers after the final data linkage and data were delivered and analysed anonymously. 


\section{Consent for publication}

Not applicable.

\section{Competing interests}

The authors declare that they have no competing interests.

\section{Author details}

'Center for Ageing and Health (Age Cap), Department of Psychiatry and Neurochemistry, Gothenburg University, SE-413 45 Gothenburg, Sweden. ${ }^{2}$ Statistikkonsulterna Jostat \& Mr Sample AB, Gothenburg, Sweden. ${ }^{3}$ Aging Research Center, Karolinska Institutet and Stockholm University, Stockholm, Sweden. ${ }^{4}$ Department of Psychiatry, Cognition and Old Age, Sahlgrenska University Hospital, Region Västra Götaland, Gothenburg, Sweden. ${ }^{5}$ Section of Epidemiology and Social Medicine, Department of Public Health and Community Medicine at Institute of Medicine, University of Gothenburg, Gothenburg, Sweden. ${ }^{6}$ Psychosis Clinic, Sahlgrenska University Hospital, Region Västra Götaland, Gothenburg, Sweden.

Received: 17 December 2019 Accepted: 11 May 2020

Published online: 16 June 2020

\section{References}

1. Troya Ml, Babatunde O, Polidano K, Bartlam B, McCloskey E, Dikomitis L, Chew-Graham CA. Self-harm in older adults: systematic review. $\mathrm{Br} J$ Psychiatry. 2019:214(4):186-200.

2. Naghavi M. Global, regional, and national burden of suicide mortality 1990 to 2016: systematic analysis for the global burden of disease study 2016. BMJ. 2019:364:194.

3. Jordan JT, MCNiel DE. Characteristics of persons who die on their first suicide attempt: results from the National Violent Death Reporting System. Psychol Med. 2019;20:1-8.

4. Szanto K, Galfalvy H, Vanyukov PM, Keilp JG, Dombrovski AY. Pathways to late-life suicidal behavior: Cluster analysis and predictive validation of suicidal behavior in a sample of older adults with major depression. J Clin Psychiatry 2018;79(2):17m11611.

5. Kenneally LB, Szücs A, Szanto K, Dombrovski AY. Familial and social transmission of suicidal behavior in older adults. J Affect Disord. 2019;245:589-96.

6. Hunt IM, Kapur N, Robinson J, Shaw J, Flynn S, Bailey H, Meehan J, Bickley $H$, Parsons R, Burns J. Suicide within 12 months of mental health service contact in different age and diagnostic groups: national clinical survey. $\mathrm{Br}$ J Psychiatry. 2006;188(2):135-4

7. Okolie C, Dennis M, Thomas ES, John A. A systematic review of interventions to prevent suicidal behaviors and reduce suicidal ideation in older people. Int Psychogeriatr. 2017;29:1-24.

8. Fässberg MM, Van Orden KA, Duberstein P, Erlangsen A, Lapierre S, Bodner $E$, et al. A systematic review of social factors and suicidal behavior in older adulthood. Int J Environ Res Public Health. 2012;9(3):722-45.

9. Hedna K, Andersson Sundell K, Hensing G, Skoog I, Gustavsson S, Waern M. Late-life suicidal behaviours among new users of antidepressants: a prospective population-based study of sociodemographic and gender factors in those aged 75 and above. BMJ Open. 2018:8(10):e022703.

10. Ludvigsson JF, Otterblad-Olausson P, Pettersson BU, Ekbom A. The Swedish personal identity number: possibilities and pitfalls in healthcare and medical research. Eur J Epidemiol. 2009;24(11):659-67.

11. Wettermark B, Hammar N, Michael Fored C, Leimanis A, Otterblad Olausson P, Bergman U, Persson I, Sundström A, Westerholm B, Rosén M. The new Swedish prescribed drug register-opportunities for pharmacoepidemiological research and experience from the first six months. Pharmacoepidemiol Drug Saf. 2007;16(7):726-35.

12. King $G$, Zeng L. Estimating risk and rate levels, ratios and differences in case- control studies. Stat Med. 2002;21(10):1409-27.

13. Morin J, Wiktorsson S, Marlow T, Olesen PJ, Skoog I, Waern M. Alcohol use disorder in elderly suicide attempters: a comparison study. Am J Geriatr Psychiatry. 2013;21(2):196-203.

14. Mäkelä P, Fonager K, Hibell B, Nordlund S, Sabroe S, Simpura J. Episodic heavy drinking in four Nordic countries: a comparative survey. Addiction. 2001;96(11):1575-88

15. Wiktorsson S, Runeson B, Skoog I, Östling S, Waern M. Attempted suicide in the elderly: characteristics of suicide attempters 70 years and older and a general population comparison group. Am J Geriatr Psychiatry. 2010;18(1):57-67.
16. Erlangsen A, Jeune B, Bille-Brahe U, Vaupel JW. Loss of partner and suicide risks among oldest old: a population-based register study. Age Ageing. 2004;33(4):378-83

17. McKenzie SK, Collings S, Jenkin G, River J. Masculinity, social connectedness, and mental health: Men's diverse patterns of practice. Am J Mens Health. 2018;12(5):1247-61.

18. Murphy E, Kapur N, Webb R, Purandare N, Hawton K, Bergen H, Waters K, Cooper J. Factors for repetition and suicide following self-harm in older adults: multicentre cohort study. Br J Psychiatry. 2012;200(5):399-404.

19. Lesen E, Wiktorsson S, Carlsten A, Waern M, Hedenrud T. Beliefs about antidepressants among persons aged 70 years and older in treatment after a suicide attempt. Int Psychogeriatr. 2015;27(11):1795-803.

20. Aarts N, Noordam R, Hofman A, Tiemeier H, Stricker BH, Visser LE. Selfreported indications for antidepressant use in a population-based cohort of middle-aged and elderly. Int J Clin Pharm. 2016:38(5):1311-7.

21. Burvill P. Migrant suicide rates in Australia and in country of birth. Psychol Med. 1998:28(1):201-8.

\section{Publisher's Note}

Springer Nature remains neutral with regard to jurisdictional claims in published maps and institutional affiliations.
Ready to submit your research? Choose BMC and benefit from:

- fast, convenient online submission

- thorough peer review by experienced researchers in your field

- rapid publication on acceptance

- support for research data, including large and complex data types

- gold Open Access which fosters wider collaboration and increased citations

- maximum visibility for your research: over $100 \mathrm{M}$ website views per year

At $\mathrm{BMC}$, research is always in progress.

Learn more biomedcentral.com/submissions 